\title{
The Anti Windup PID Controller ISE Tuning Based for Small-Scale Steam Distillation System
}

\author{
Haslizamri Md Shariff, Mohd Hezri Fazalul Rahiman, Ramli Adnan, Mohd Hezri Marzaki, Mazidah \\ Tajjudin, Mohd Hafiz A. Jalil
}

\begin{abstract}
Proportional-Integral-Derivative (PID)controller are easy to develop and tuned, efficient and reliable in any control system areas. The main problem of PID controller when a system facing unwanted windup phenomena due to existence of input saturation. This phenomenonis occur due to failure of controller to unwind the control input signal. The objective of this paper is to develop the Proportional-Integral-Derivative integrated AntiWindup (PIDAW) controllers in order to diminish windup phenomenon using the tracking calculation tuning by Integral Square Error (ISE). The simulation results show that the proposed PIDAW controller is capable to reduce the overshoot and faster settling time. It is proven that PIDAW controller has better performance compared to the conventional PID controller.
\end{abstract}

Index Terms-Proportional (P), Integral (I), Derivative (D), Integral Absolute Error (IAE), Integral Square Error (ISE) and Integral Time Absolute Error (ITAE), PID integrated Anti Windup (PIDAW).

\section{INTRODUCTION}

Since 1930, PID controllers are widely utilized in industrial processes due to easy to develop and tuned, efficient and reliable in any control system areas[1], [2]. Until today, more than 500 tuning methods have been derived to tune the PID controllers in order to achieve best performance[3]. However, no general claim that signifies which method would produce the best tuning.

The problem of conventional PID controllers whena system exhibit nonlinearities in their dynamic and windup phenomenon will occur. In addition, the limitation of controller capability to unwind the presence of the phenomenonand control signal will fluctuate beyond the upper or limit of actuator operation level.

The windup phenomenon occur when the integral action from controller reach at maximum level and controller feedback does not affect anymore. The output of controller start to increase; where an integral action non-stop accumulate without realize it's already produce some error to the system. The value of integrator increase and undesired error controller signal is produced which are ouside the operating region of the actuator operation[4].

This manuscript is submitted on $26^{\text {th }}$ July 2019 and accepted on $05^{\text {th }}$ February 2020. Haslizamri Md Shariff, Mohd Hezri Fazalul Rahiman, Ramli Adnan, Mohd Hezri Marzaki and Mazidah Tajjudin are with the Faculty of Electrical Engineering, Universiti Teknologi MARA, 40450 Shah Alam, Selangor (e-mail: hezrif@ieee.org)

Mohd Hafiz A. Jalil is with Faculty of Electrical and Electronic, Universiti Tun Hussein Onn Malaysia, 86400 Parit Raja, Johor.

1985-5389/C 2021 The Authors. Published by UiTM Press. This is an open access article under the CC BY-NC-ND license (http://creativecommons.org/ licenses/by-nc-nd/4.0/).
The situationcan cause actuator saturation level broken the fedback loop function[5]; feedback loop not function anymore and causing high overshoot, longer settling time and instability dynamic[5]-[7]. The problem of windup occur in a control system must be considered when designing a controller to reach best performance of close-loop system [4].

In other word, this phenomenon occurs due to failure of controller to unwind the control input signal[8]. Input saturation situation is common nonlinearities phenomenon in control system. The phenomenon occur when actuator operation is achieved the saturation point level and input of a plant will be different from the controller output[9]. Consequently,an integrator start to integrate an error and wind up start to occur.

In steam distillation process, PID controller utilized widely to control the whole process[10]-[14]. Unfortunately, only few number of research tune a PID controller and consider the windup phenomenon problem in steam distillation system[15]-[17].Until today, almost all works related to control the steam of distillation column only focusing on development of PID without consider unwanted windup phenomena[6], [17].

The basic PID structure suffers to control windup phenomenon due to the presence of the most encountered nonlinearities on the system caused by control input constraint[6]. The problem is associated with the integral action on the PID controller itself. The integral action is continuously integrate an error and start to produce too large controller signals which are beyond the upper or lower limit of the actuator operation; known as windup phenomenon[18], [19]. The phenomenon will cause actuator saturation level broken the system feedback loop function. The windup problem will effect the efficiency of a system; where produce undesired close-loop performance which produced by the PID controller such as high overshoot, steady state error and instability dynamic[6], [20], [21].

The unwanted windup problem could be solved by implementation of PID integrated Anti Windup (PIDAW) controller. This paper propose the solution to overcome windup phenomenonproblem using PID integrated AntiWindup (PIDAW) controller tuned by Integral Square Error (ISE) method. The function of anti-windup action integrated in classical PID structure is to minimizebad effect of control input nonlinearities in close loop system performance [22]. 


\section{BASIC PID STRUCTURE AND PID INTEGRATEDANTI-WINDUP} STRUCTURE

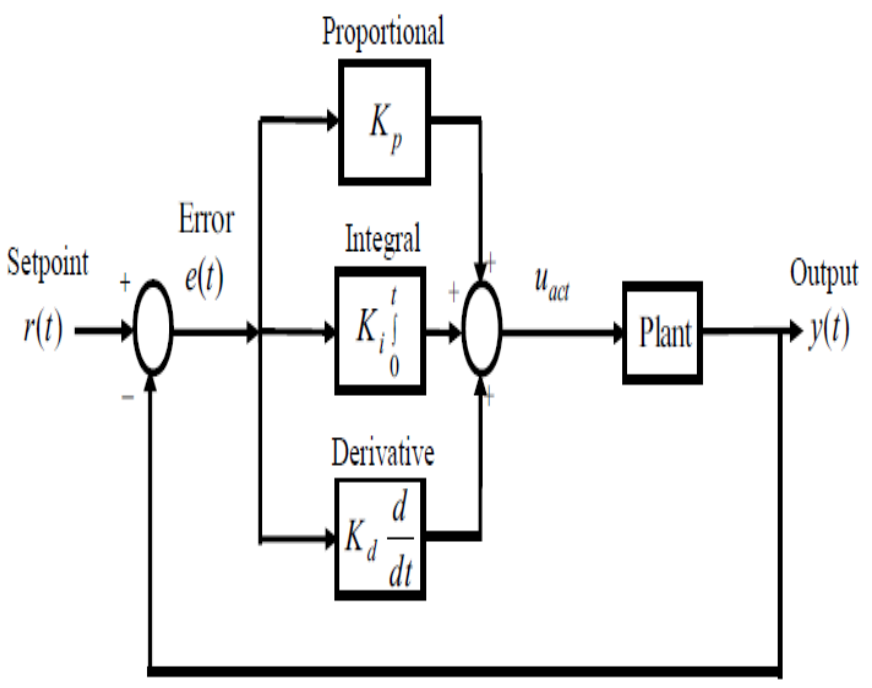

Fig. 1: Basic PID Controller Block Diagram

Fig. 1 shows the basic PID controller block diagram.The PID or so called "three terms" controller because it is a combination of a three modes which $P$ (Proportional mode), $I$ (Integral mode), and $D$ (Derivative mode) [14]. The principle of PID controller is monitor an error occur between a measured process variable and a desired set point. Based on value of error, a corrective signal will be computed and eventually feed back to the input to improve a process accordingly.

The general PID control structure is expressed in equation (1)

$u(t)=K\left(e(t)+\frac{1}{T_{i}} \int_{0}^{t} e(t) d t+T_{d} \frac{d e(t)}{d t}\right)$

where $u(t)$ is the input control signal and $e(t)$ is the error signal where the $e(t)=Y(s)-X(s)$. The development of PID controller is tuning by ISE method. Proportional gain is calculated by equation (2)

$K_{p}=\frac{1.473(}{k}\left(\frac{\theta}{\tau}\right)^{-0.970}$

And, Integral Time Contsant is computed by equation (3)

$T_{i}=\frac{\tau}{1.115}\left(\frac{\theta}{\tau}\right)^{0.753}$

Then, Derivative Time Constant is expressed by equation (4)

$T_{d}=0.550 \tau\left(\frac{\theta}{\tau}\right)^{0.9480}$
The PID controlleris able to control a system response at a desired set point so that there is no error between output signal and desired set point. The PID parameter's have their own function where the proportional gain gives output which is proportional to current error, $e(t)$. It compares between reference signalversus output value and; resulting error is multiplied with proportional constant to obtain the output signal. Due to limitation of proportional gain, the integral action is neededto improve the steady state error. The integral action will improve the steady state error so that the output is close to desired set point. Meanwhile, derivative action is to improve the system response by anticipating future behavior of the error.

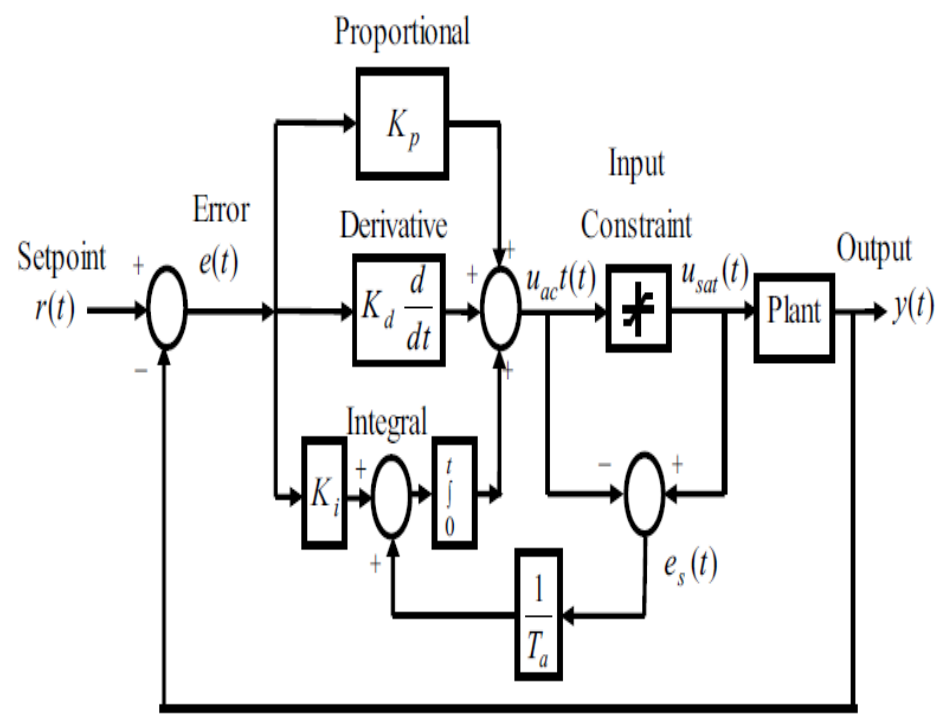

Fig. 2: PID integrated Anti Windup (PIDAW) Controller Block Diagram

Fig. 2 shows the PID Integrated Anti Windup (PIDAW) controller block diagram. The basic PID controller as compared to PID Integrated Anti-Windup (PIDAW) strategies can be expressed based on additional feedback $\left(1 / T_{a}\right)$ integrated in PIDAW.The function of additional feedback is to compute the different value of saturated control signal, $u_{\text {sat }}$ and unsaturated/actual control signal, $u_{\text {act }}$.

Once the $u_{a c t}$ goes beyond the saturated level, the residual value of $u_{\text {sat }}$ and $u_{a c t}$ will befeed backto integrator via $1 / T_{a}$ gain to recalculate the new integral action term. The process is continuously occur until the value of integral term $1 / T_{a}$ to form $u_{\text {act }}(t)$ lies on the saturation limit of the system.

The successful of PIDAW controller using tracking calculation is highly depending on selection of Tracking Time Constant, $T_{a}$ value[6].The determination of $T_{a}$ value will influent the how fast an integral term rate is being reset and this phenomenon indirectly effect on overall controller performance[23]. Ioannouet. al[24] suggest that the $T_{a}$ value is within the range shown in equation (2)

$T_{i} \geq T_{a} \geq T_{d}$

And, Astromet al.[25]are proposed the determination of $T_{a}$ value shown in (3)

$T a=\sqrt{ }(T i T d)$ 
Referring to equation (3) proposed by Astromet. al [25],the value of $T_{a}$ is within the range of equation (2); which proposed byIoannouet. al[24].Hence, to study the performance integrator feedback; three selected Tracking Time Constant, $T_{a}$ will be manipulated in the range of equation (2). The proposed of $T_{a}$ values can be expressed by equation (4)-(6)

$$
\begin{aligned}
& T_{a}=T_{i} \\
& T_{a}=T_{d} \\
& T_{a}=\sqrt{ }\left(T_{i} T_{d}\right)
\end{aligned}
$$

The equation (4)-(6) will be applied for new integral action term in PIDAW controllers. The selected $T_{a}$ value will be analysed to determine which controller is able to achieve good performance index.

\section{CONTROLLER PERFORMANCE INDEX}

In order to evaluate the performance of controller, three performance index are utilized: ISE, IAE and ITAE based on the numerical method.

The ISE performance index integrates the square of errorfrom a system via a period of time. The performance index scale will penalized larger errors occur compared to the smaller one since the square of large error will be much bigger. The ISE is given by

ISE performance index $=\int \varepsilon^{2} d t$

The IAE performace index integrates the absolute of error occur in a system over a period of time. The IAE performance index do not accumulate weight to any of the error that occur in a system reponse. The IAE is given by

$I A E$ performance index $=\int|\varepsilon| d t$

The ITAE performance index integrates an absolute error from a system multiplied by the time over a period of time. The ITAE will penalized the error occur heavily compared to initial response of a system. The ITAE is given by

ITAE performance index $=\int t|\varepsilon| d t$

\section{THE SIMULATION OF STEAM DISTILLATION SYSTEM}

The MATLAB2018 software is applied to develop simulation system for steam distillation process. The transfer function for steam distillation system is developed from process reaction curve; which is obtained from actual process of small-scale steam distillation system. The process reaction curve is able to reveal an actual dynamic of a system where three main components will be obtained; gain $(k)$, dead time $(\theta)$ and time constant $(\tau)$.

The steam distillation experiment was conducted at Distributed Control System (DCS) Laboratory in Faculty of Electrical Engineering, UiTM Shah Alam.

The small-scale steam distillation plant as in Fig. 4 was designed to extract and produce essential oilsby applied the steam distillation technique. The small-scale steam distillation systemis built by several components such as stainless steel distillation tank with diameter $30 \mathrm{~cm}$, water-cooled copper condenser, two resistive-temperature detector (RTD) assensoring element's to measure steam and water temperatures, control panel and data acquisition compartment. The stainless steel distillation column for the plant have the maximum capacity of 25 liters. During the extraction of essential oils process, the raw material is placed inside the distillation column.

In initial stage of development of controller to control steam temperature of distillation process, only water is placed in the distillation tank. The water will be heated by heater placed at bottom of distillation tank. The step signal was injected to the plant with maximum voltage $5 \mathrm{~V}$ to study the actual behavior of the system. The dynamic of steam distillation system will be recorded and calculated using First Order Plus Dead Time (FOPDT) method. Thepocess reaction curve in Fig. 3 revealed the behavior of the system and three main parameters; gain, time constant and dead time will be calculated. The parameterscalculation of process are shown in Equation (10)(21).

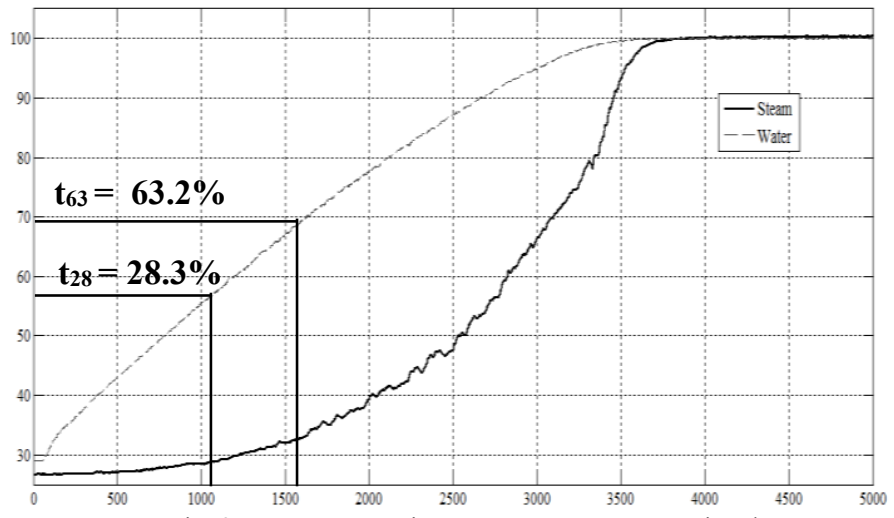

Fig. 3: Process Reaction Curve By Step Input Signal

Gain, $K=\frac{\Delta y}{\Delta u} ; 0 \mathrm{~V}$

$K=\frac{100-25}{5 V-0 V}$

$K=15$

Time Constant, $\tau=1.5\left(\mathrm{t}_{63}-\mathrm{t}_{28}\right)$

Where $\mathrm{t}_{63}=1562$ and, $\mathrm{t}_{28}=1031$ 
Time constant, $\tau=1.5(1562-1031)$

Time constant, $\tau=796.5$

Dead Time, $\theta=t_{63}-\tau$

Dead Time, $\theta=1562-796.5$

Dead Time, $\theta=765.5$

From the three main parameters; Gain, Time Constant and Dead Time are utilized to develop FOPDT model and represent the actual behavior of the process dynamic. The Equation (20) and (21) illustrates the FOPDT model for the Small-scale Steam Distillation plant.

$\frac{Y(s)}{X(s)}=\frac{K e^{-\theta s}}{\tau s+1}$

$\frac{Y(s)}{X(s)}=\frac{15 e^{-765.5 s}}{796.5 s+1}$

The FOPDT model is applied in simulation process in order to study the performance of developed controllers. The PID controllers are tuned based on ISE method. It also integrated with anti windup scheme using the difference Tracking Time Constant values.

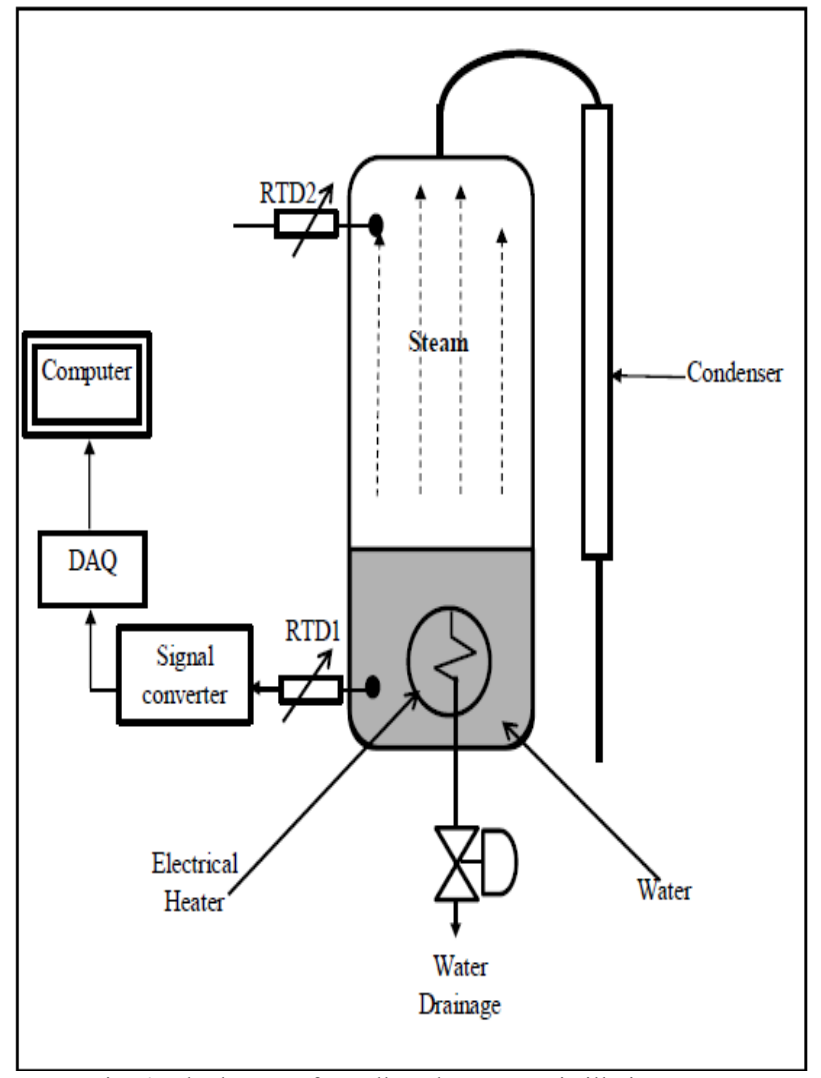

Fig. 4: The layout of Small-scale Steam Distillation System

\section{Simulation RESUlts}

Table 1 shows the summary data for ISE-PID and enhancement of all ISE-PIDAW performances in step test simulation studies and also transient response illustrated in Fig. 5. The enhancement of all ISE-PIDAW controllers show significant inprovement in overshoot percentage. The settling time also, show significant improvement are achieved by all ISE-PIDAW controllers compared to the ISE-PID. The IAE, ISE and ITAE performances index also indicate less error computed for ISE-PIDAW controllers compared to the ISEPID.

Fig. 6 shows the percentage improvement of overshoot from ISE-PID controller to all ISE-PIDAW controllers for ISEPIDAW- $\sqrt{(T i T d), ~ I S E-P I D A W-T i ~ a n d ~ I S E-P I D A W-T d . ~ B y ~}$ rank, the best improvement is obtained from ISE-PIDAW-Td controller, which achieved at $62.16 \%$ and, followed by the

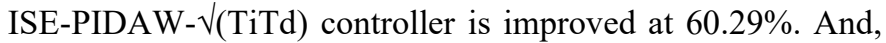
third is ISE-PIDAW-Ti which achieved $57.56 \%$. In general, the improvement achived by all ISE-PIDAW controllers over the ISE-PID controller are significant. Overall, the scenario is showed that the ISE-PIDAW controllers have outperformed the ISE-PID controller.

TABLE 1

Summary Data for Various Controller Performance in STEP Test SIMULATION STUDIES

\begin{tabular}{|c|c|c|c|c|}
\hline $\begin{array}{c}\text { Performance } \\
\text { Index }\end{array}$ & ISE-PID & $\begin{array}{l}\text { ISE-PIDAW- } \\
\sqrt{\left(\mathbf{T}_{\mathrm{i}} \mathbf{T}_{\mathrm{d}}\right)}\end{array}$ & $\begin{array}{c}\text { ISE- } \\
\text { PIDAW- } \\
\text { Ti }\end{array}$ & $\begin{array}{c}\text { ISE- } \\
\text { PIDAW- } \\
\text { Td }^{\#} \\
\end{array}$ \\
\hline OS\% & $36.17 \%$ & $14.36 \%$ & $15.35 \%$ & *13.69\% \\
\hline Ts & $\begin{array}{c}1.2692 \\
\times 10^{4}\end{array}$ & $\begin{array}{c}0.86090 \\
\times 10^{4}\end{array}$ & $\begin{array}{c}0.86553 \\
\times 10^{4}\end{array}$ & $\begin{array}{c}* 0.85814 \\
\times 10^{4}\end{array}$ \\
\hline $\mathrm{Tr}$ & $\begin{array}{c}* 2.3529 \\
\times 10^{3}\end{array}$ & $\begin{array}{c}2.3530 \\
\times 10^{3}\end{array}$ & $\begin{array}{c}* 2.3529 \\
\times 10^{4}\end{array}$ & $\begin{array}{c}2.3548 \\
\times 10^{4}\end{array}$ \\
\hline IAE & $\begin{array}{c}5.6760 \\
\times 10^{4}\end{array}$ & $\begin{array}{l}5.6020 \\
\times 10^{4}\end{array}$ & $\begin{array}{l}5.6050 \\
\times 10^{4}\end{array}$ & $\begin{array}{c}* 5.6000 \\
\times 10^{4}\end{array}$ \\
\hline ISE & $\begin{array}{c}1.7550 \\
\times 10^{4} \\
\end{array}$ & $\begin{array}{c}1.5340 \\
\times 10^{4} \\
\end{array}$ & $\begin{array}{c}1.5430 \\
\times 10^{4}\end{array}$ & $\begin{array}{c}* 1.5270 \\
\times 10^{4}\end{array}$ \\
\hline ITAE & $\begin{array}{c}1.4700 \\
\times 10^{9}\end{array}$ & $\begin{array}{c}* 1.4510 \\
\times 10^{9}\end{array}$ & $\begin{array}{c}1.4520 \\
\times 10^{4}\end{array}$ & $\begin{array}{c}* 1.4510 \\
\times 10^{4}\end{array}$ \\
\hline
\end{tabular}




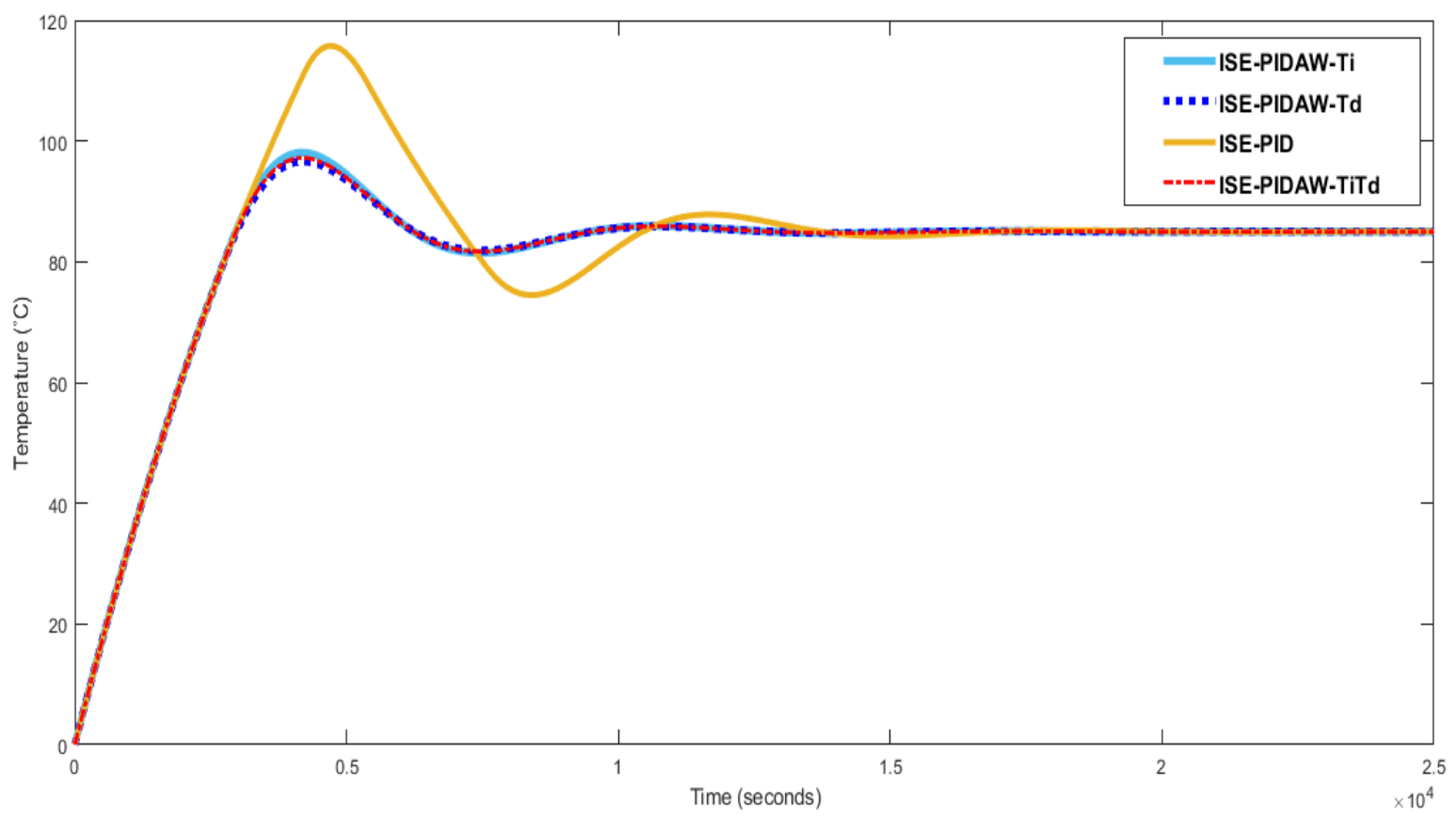

Fig. 5: Output for ISE-PID, ISE-PIDAW-Ti, ISE-PIDAW-Td and ISE-PIDAW- $\sqrt{ }\left(\mathrm{T}_{\mathrm{i}} \mathrm{T}_{\mathrm{d}}\right)$ Controllers in Step Test Simulation.

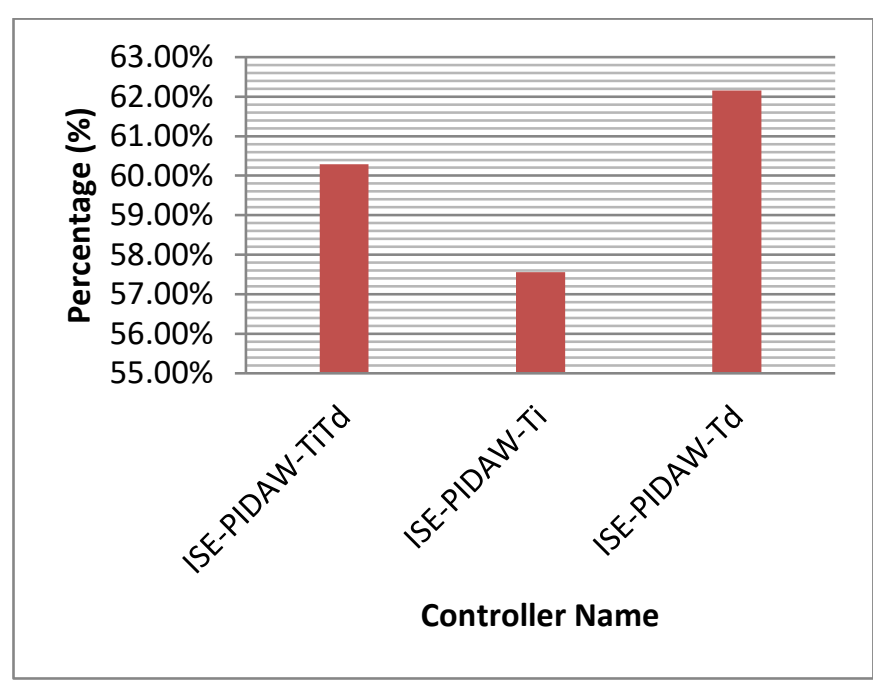

Fig. 6: Percentage overshoot improvement from ISE-PID to ISE-PIDAW controllers for ISE-PIDAW-Ti, ISE-PIDAW-Td and ISE-PIDAW- $\sqrt{(T i T d)}$.

The simulation result for ISE-PID and ISE-PIDAW controllers on recovering the set point $85^{\circ} \mathrm{C}$ are shown in Fig. 7. The qualitative result indicate that all the ISE-PIDAW controllers are able to return to the set point faster than ISEPID controller. The best improvement is obtained from ISEPIDAW-Td controller, which achieved 32.3\%. ThenISEPIDAW- $\sqrt{(\text { TiTd }) ~ c o n t r o l l e r ~ i s ~ i m p r o v e d ~ a t ~} 32.1 \%$, and the ISE-PIDAW-Tiis $31.8 \%$ recorded. In general, the improvement achived by all ISE-PIDAW controllers over the ISE-PID controller are significant. Overall, the scenario is showed that theISE-PIDAW controllers have outperformed the ISE-PID controller.

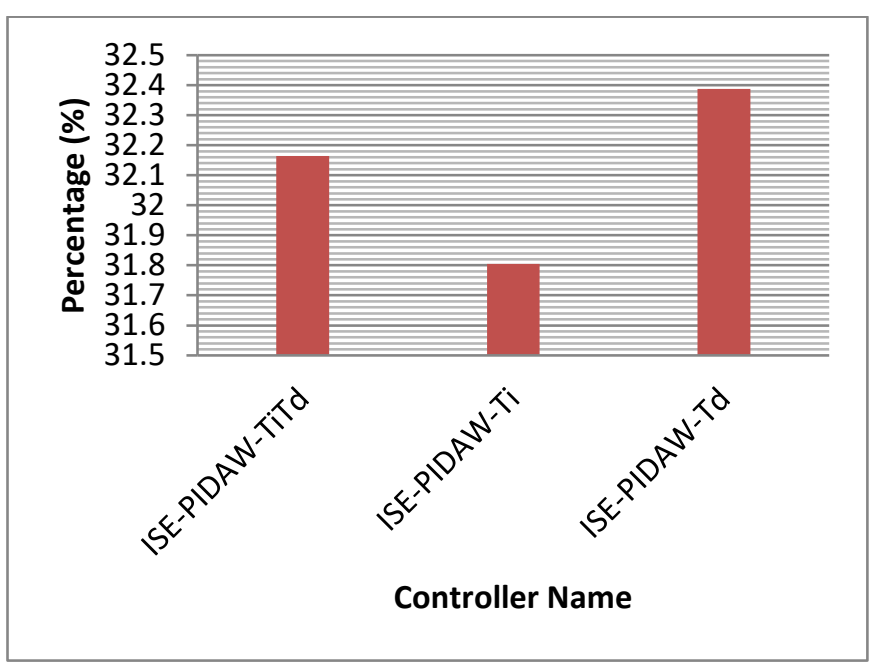

Fig. 7: Percentage improvement of Settling time from ISE-PID to ISEPIDAW controller for ISE-PIDAW-Ti, ISE-PIDAW-Td and ISE-PIDAW$\sqrt{ }(\mathrm{TiT})$.

\section{CONCLUSION}

Based on the simulation results, all the ISE-PIDAW controllerstuning based on Integral Square Error using tracking calculation shows improvement in all performance index. The proposed of Tracking Time Constant, $T_{a}$ values are capable to reduce the windup phenomenon occurred in simulation of small-scale steam distillation system. Based on ranking, thebest controller ISE-PIDAW-Td show lowest percentage of overshoot and $62.16 \%$ improvement of overshoot compared to the ISE-PID. And, the second best controller is the ISE-PIDAW- $\sqrt{(T i T d)}$ show $60.29 \%$ improvement of overshoot compared to the ISE-PID. From the 
overall comparison between the ISE-PID and ISE-PIDAW controllers, all theISE-PIDAW controllers have shown to be advantageous in all aspects. In this study, all theISE-PIDAW controllershave successfully improved the overshoot and settling time of the system over $30 \%$.

\section{REFERENCES}

[1] W. Upaphai, P. Bunyawanichakul, and M. Janthong, "Design of Self-tuning Fuzzy PID Controllers for Position Tracking Control of Autonomous Agricultural Tractor," Pertanika J., vol. 27, no. 1, pp. 263-280, 2019.

[2] M. Tabatabaei and R. Barati-boldaji, "Non-overshooting PD and PID controllers design," Autom. J. Control. Meas. Electron. Comput. Commun., vol. 58, no. 4, pp. 400-409, 2018.

[3] P. Mhaskar, "A Method for PID Controller Tuning Using Nonlinear Control Techniques"," Proceeding 2004 Am. Control Conf. Boston, Massachusetts, pp. 2925-2930, 2004.

[4] S. Galeani, S. Tarbouriech, M. Turner, and L. Zaccarian, "A Tutorial on Modern Anti-windup Design," Eur. J. Control, vol. 15, no. 3-4, pp. 418-440, 2009.

[5] Karl Johan Astrom, "Feedback Systems," Book $2^{\text {nd }}$ Edition, PrincetonUniversity Press Princetonand Oxford, 2002.

[6] Muhamad Hafiz Abd Jalil, "Model Reference Adaptive Control (MRAC) Controller Towards Temperature Regulation Improvement of Glycerin Bleaching Process", PhD Dissertation, University Technology MARA Malaysia, 2019.

[7] R. Lucian, C. C. Rodolfo, C. C. Rodolfo, and J. E. Normey-rico, "Analysis of Anti-windup Techniques in PID Control of Processes with Measurement Noise," Elsevier Sci., vol. 51, no. 4, pp. 948953, 2018.

[8] W. U. Xiongjun and L. I. N. Zongli, "Dynamic anti-windup design for anticipatory activation: enlargement of the domain of attraction," Sci. CHINA Inf. Sci., vol. 57, no. January, pp. 1-2, 2014.

[9] R. Precup, M. L. Tomescu, and E. M. Petriu, "A Unified AntiWindup Technique for Fuzzy and Sliding Mode Controllers Models of State Feedback Sliding Mode and Fuzzy Control Sys- tems," Int. J. Comput. Commun. Control, vol. 10, no. 6, pp. 843-855, 2015.

[10] N. Kasuan, M. H. A. Jalil, M. Hezri, F. Rahiman, and M. N. Taib, "A Discrete Model Reference Adaptive Control for Temperature Tracking in Steam Distillation Process," in 2015 IEEE 11th International Colloquium on Signal Processing \& its Applications (CSPA2015), 6 -8 Mac. 2015, Kuala Lumpur, Malaysia, 2015, pp. 6-8.

[11] Z. M. Yusoff, Z. Muhammad, M. Hezri, F. Rahiman, and M. N. Taib, "Application of Hybrid Fuzzy plus PID for Steam Temperature Control in Hydro-diffusion Essential Oil Extraction System," in IEEE 10th International Colloquium on Signal Processing \& its Applications (CSPA2014), 2014, pp. 7-9.

[12] Z. Muhammad et al., "Online Tuning PID using Fuzzy Logic Controller with Self- T uning Method," in IEEE 3rd International Conference on System Engineering and Technology, 2013, pp. 1920.

[13] M. H. Marzaki, M. H. A. Jalil, H. Shariff, and R. Adnan, "Comparative Study of Model Predictive Controller ( MPC ) and PID Controller on Regulation Temperature for SSISD Plant," IEEE 5th Control Syst. Grad. Res. Colloq., pp. 136-140, 2014.

[14] Mohd Hezri and Marzaki, "Modelling and Control of Distillation Plant using Fractional-order PID Controller Integrated with Error and Low Pass Filter." Phd Dissertation, Universiti Teknologi MARA Malaysia, 2017.

[15] P. Kheirkhahan and E. Engineering, "Robust Anti-Windup Control Design for PID Controllers," in 2017 17th International Conference on Control, Automation and Systems, 2017, no. Iccas, pp. 16221627.

[16] P. Liu, P. Yan, S. Member, and Z. Zhang, "Robust Anti-Windup Compensation for High Precision Tracking of a Piezoelectric NanoStage," IEEE Trans. Ind. Electron., vol. 0046, no. c, 2016.

[17] H. Jigang, W. Jie, and F. Hui, "An anti-windup self-tuning fuzzy PID controller for speed control of brushless DC motor," Automatika, vol. 58, no. 3, pp. 321-335, 2018.
[18] L. Zhou, C. Wang, Q. Wang, and C. Yang, "Anti-windup control for nonlinear singularly perturbed switched systems with actuator saturation,” Int. J. Syst. Sci., vol. 0, no. 0, pp. 1-15, 2018.

[19] X. W. and Z. Lin, "On Immediate, Delayed and Anticipatory Activation of Anti-Windup Mechanism: Static Anti-Windup Case," IEEE Trans. Automat. Contr., vol. 57, no. 3, pp. 771-777, 2012.

[20] E. C. El Alaoui, H. Ayad, and S. Doubabi, "Fuzzy Anti-Windup Schemes for PID Controllers," Int. J. Appl. Eng. Res., vol. 1, no. 3, pp. 295-306, 2006.

[21] V. Ilioudis and N. Margaris, "Antiwindup Speed Technique for Sensorless Control of Synchronous Machine Using Saturation Feedback," in 20th Mediterranean Conference on Control \& Automation (MED), 2012, pp. 1007-1012.

[22] E. F. Mulder, P. Y. Tiwari, and M. V Kothare, "Simultaneous linear and anti-windup controller synthesis using multiobjective," Automatica, vol. 45, no. 3, pp. 805-811, 2009.

[23] K. J. Astrom and R. M. Murray, Feedback Systems. Princeton University Press Princeton And Oxford, 2012.

[24] P. A. Ioannou and P. V. Kokotovic, "Instability analysis and improvement of robustness of adaptive control," Automatica, vol. 20, pp. 583-594, 1984.

[25] J. Astrom and T. Hagglund, PID Controllers:Theory, Design and tuning, 2nd ed.: Instrument Society of America (ISA). 1995. 